\title{
Lesions of Lip and Tongue
}

\author{
B.N.Radhika ${ }^{1}$, Dr. Arathy S. Lankupalli \\ (C.R.R.I, Department of Oral Medicine and Radiology, Saveeetha University, India) \\ (M.D.S, Senior Lecturer, Department of Oral Medicine and Radiology, Saveeetha University, India)
}

\begin{abstract}
The main aim of this review article is to highlight the most important clinical features of the lesions occurring on the lip and the tongue. Black hairy tongue, a disorder seen on the dorsum of the tongue showing a hairy appearance ${ }^{I}$, actinic chelitis- the main precancerous lesion of the lip ${ }^{2}$, oral hairy leukoplakia- a disorder of tongue seen in immunocompromised patients ${ }^{3}$, lymphangiomas which are the malformations of lymphatic vessels ${ }^{4}$, hemangiomas- the benign malformations of blood vessels occurring in the head and neck ${ }^{5}$, orofacial granulomatosis- a chronic inflammatory disorder characterized by persistent or recurrent soft tissue enlargement ${ }^{6}$, mucocele- a benign, mucus containing cystic lesion of the minor salivary glands ${ }^{7}$ and carcinoma occurring on the lip and the tongue are the various lesions described in this article for a better understanding. The data collection for this review article was carried out independently through various published articles and online search.
\end{abstract}

Keywords: Actinic Chelitis, Hairy Leukoplakia, Hemangioma, Lymphangioma, Mucocele, Orofacial Granulomatosis,

\section{Introduction}

The various lesions affecting the lip and tongue have been enlisted here.

They include:

$>$ Mucocele- a lesion occurring mainly on the lower lip occurring due to trauma ${ }^{8}$.

$>$ Actinic cheilitis, affecting mostly the fair skinned individuals which have the potential to proceed to malignancy'.

$>$ Orofacial granulomatosis- characterized by orofacial swelling of unknown etiology ${ }^{10}$.

$>$ Lymphangioma- a developmental malformation occurring in the head and neck region ${ }^{11}$.

$>$ Hemangioma- they are abnormalities of blood vessels mostly seen in infancy ${ }^{12}$.

$>$ Black hairy tongue- a benign, painless disorder caused due to defective desquamation of the filiform papillae of the tongue ${ }^{13}$

$>$ Oral hairy leukoplakia-, a non-painful white lesion seen mainly on the tongue ${ }^{14}$.

$>$ Carcinoma occurring on the tongue and the lips presented as recurrent or persisting non healing ulcers which are painful and often show lymph node involvement. They are treated by surgery or radiotherapy or a combination of both ${ }^{15}$.

\subsection{MUCOCELE}

\section{Discussion}

Also known as mucus extravasation phenomenon, mucus escape reaction ${ }^{8}$.A mucocele is a benign, mucus-containing cystic lesion of the minor salivary gland ${ }^{7}$.It is a common lesion of the oral mucosa that results from rupture of a salivary gland duct and spillage of mucin into the surrounding soft tissues. This spillage is often the result of local trauma ${ }^{8}$. There are three clinical variants: superficial mucocele, classic variant and the deep mucocele. Their most common site for their occurrence is the lower lip ${ }^{7}$.

2.1.1 Clinical presentation: They are mucus containing cystic lesions which presents as a distinct, fluctuant, painless swelling of the mucosa. They take up a bluish to translucent hue, whereas the deep lesions have normal mucosal appearance and bleeding may impart a bright red and vascular appearance ${ }^{7,8}$.

2.1.2 Treatment: Some mucoceles are short lived lesions that rupture and heal by themselves. The chronic lesions need to be treated by a local surgical excision. To minimize the risk of occurrence, it is recommended to remove the adjacent minor salivary gland that may be feeding into the lesion ${ }^{7,8}$. 


\subsection{ACTINIC CHELITIS}

It is a chronic inflammatory process affecting the lower lip. It is a common premalignant alteration of the lower lip vermilion that results from long term or excessive exposure to the ultraviolet component of sunlight ${ }^{9}$.It is considered as a potentially malignant lesion of high morbidity which can develop into invasive squamous cell carcinoma ${ }^{2}$.

2.2.1 Clinical presentation: It usually affects fair skinned individuals with a history of chronic sun exposure and can occur at any age ${ }^{2}$. Usually there is loss of the sharp borders of the lip, atrophy of the vermilion border and darkening of the lip at the border between the lip and the skin of the face ${ }^{2}$. Rough and scaly areas develop, which become thick, especially when they extend to the wet line of the lip. Chronic focal ulceration can occur in one or more sites ${ }^{2}$. Leukoplakia, the most common form of AC and the most common change that precedes squamous cell carcinoma of the oral mucosa is also noticed in some cases ${ }^{2}$.

2.2.2 Treatment: Most of the changes associated with $\mathrm{AC}$ are irreversible, but the patients should be encouraged to use lip balms with sunscreens to prevent further damage ${ }^{9}$. Biopsy is recommended for those cases of AC where there is loss of the usually sharp line marking the transition between the red of the lip and the normal $\operatorname{skin}^{2,9}$.

\subsection{OROFACIAL GRANULOMATOSIS}

Orofacial granulomatosis is a chronic inflammatory disorder characterized by persistent or recurrent soft tissue enlargement, oral ulceration, and a variety of orofacial features.The term was proposed by Wiesenfield et al. in 1985. It is an uncommon but increasingly recognized disease of unknown etiology.

2.3.1 Clinical presentation: It is a disease with a wide spectrum of clinical presentation. It usually presents as a diffuse swelling of the lower lip. The labial tissues demonstrate a non-tender, persistent swelling, soft to firm in consistency that may involve one or both the lips.

Biopsy reveals circumscribed aggregates of non-caseating granulomatous inflammation consisting of lymphocyte and epitheloid histiocytes with multinucleated giant cells. The conditions with granulomatous lesion histologically include Crohn's disease, sarcoidosis, TB, hypersensitivity reaction, and angioneurotic edema. It is also referred to as a mono-symptomatic variant of Melkersson-Rosenthal syndrome and as granulomatous cheilitis when localized to the perioral tissues.

\subsection{LYMPHANGIOMA}

Lymphangiomas are developmental malformations which have a marked predilection for the head and neck region. They are benign proliferation of the lymphatic vessels and represent hamartomas of malformed lymphatics ${ }^{16}$.

The most common location in the mouth is the dorsum of the tongue, followed by the lips, buccal mucosa, soft palate, and floor of the mouth. They may represent as localized or a diffused growth which may enlarge to cause macroglossia, impaired speech and difficulty in mastication ${ }^{4}$.

They represent typically at birth, but may go unnoticed until after dentition erupts or even after puberty.

2.4.1 Clinical presentation: There are three different types of lymphangiomas:

a) Capillary lymphangioma(lymphangioma simplex)- consists of small, capillary sized vessels

b) Cavernous lymphangioma- composed of larger dilated lymphatic vessels

c) Cystic lymphangioma- which exhibits large, macroscopic cystic spaces ${ }^{17}$.

The most common site of occurrence is the anterior two thirds of the tongue, where they often result in macroglossia. The tumor that arises is usually superficial in location and demonstrates a pebbly surface which resembles a cluster of translucent vesicles ${ }^{4}$.

The growth may be localized or diffused. Localized lymphangiomas occur as nodular tumors elevated above the surface of the tongue. Usually there is a plaque constituted from small vesicles with thin walls, translucide like frog eggs. Part of the vesicle are full with clear content (lymph), part has blood content suggesting co-existence of involvement of the lymphatic anomalies with abnormalities of the blood vessels ${ }^{17}$.

2.4.2 Treatment: Treatment of lymphangioma depends upon their size, type, involvement of anatomical structures and infiltration to the surrounding tissues. It is aimed at complete surgical excision. Partial surgical excision, injection of sclerosing solutions, electrocoagulation, cryotherapy, embolization, steroid administration, and radiation and laser surgery may be the other modalities of treatment of diffuse lymphangioma of the tongue ${ }^{4}$. 


\subsection{HEMANGIOMA}

Hemangioma is one of the most common terms which are used to describe developmental vascular anomalies. They are benign malformations of blood vessels mostly seen in infancy that display a rapid growth phase with endothelial cell proliferation, followed by gradual involution. They can be diagnosed based on history and physical examination ${ }^{12}$. The etiology of hemangiomas remains unknown. It is reported that childbearing age, gestational hypertension and infant birth weight may be related to the formation of hemangioma ${ }^{18}$.

There are three types of hemangiomas:

a) capillary type

b) cavernous type

c) capillary and cavernous mixed type ${ }^{12}$

2.5.1 Clinical presentation: Hemangiomas may be present at birth, but they develop in the first few weeks after birth. They usually manifest as patches which appear dull and pale, could be easily neglected, and then grow rapidly. It then appears as a port wine stain like lesion.

The main characteristic feature includes a rapid proliferative phase followed by an involutive phase. The growth rate of the proliferative tumor is faster than that of the development of the infant. This is followed by problems such as nasal obstruction, ulceration, visual problems and airway obstructions.

2.5.2 Treatment: The treatment of hemangiomas is dependent on the various stages of growth. The basic principles include:

Small isolated or multiple skin lesions on the face found after birth should be treated as soon as possible in order to prevent its progress. The proliferative stages should be treated with drug therapy as indicated. Systemic corticosteroids may help to reduce the size of the lesion. Intralesional and topical corticosteroids have also been used for small localized, problematic lesions.

Laser therapy (argon laser, pulsed dye laser and Nd:YAGlaser, semiconductor laser, etc), Scleotherapy (intratumoral injection of steroids, pinyangmycin, interferon a) for deep or large hemangiomas a combination of drugs combined with laser therapy ${ }^{12,18}$.

\subsection{BLACK HAIRY TONGUE}

Also known as lingua villosa nigra, is a benign disorder caused by defective desquamation and reactive hypertrophy of the filiform papillae of the tongue. The hairy appearance is due to elongation of keratinized filiform papillae, which may have different colors. It varies from white to yellowish brown to black depending upon the extrinsic factors like tobacco, coffee, tea etc. and intrinsic factors like chromogenic organisms in normal flora.

2.6.1 Clinical presentation: It is usually asymptomatic. But sometimes symptoms like altered metallic taste, nausea, or halitosis may be noted. Tobacco use and drinking coffee and tea are also contributory factors. Neurological factors like trigeminal neuropathy may be associated.

2.6.2 Treatment: It usually does not require any treatment with drugs but if associated with fungal growth, a topical anti-fungal can be used when the condition is symptomatic.

Brushing or scraping the tongue, improving oral hygiene and elimination of potential offending factors is usually sufficient to resolve the lesions ${ }^{1,19}$.

\subsection{MEDIAN RHOMBOID GLOSSITIS}

It is defined as the central papillary atrophy of the tongue. Typically located around the midline on the dorsum of the tongue ${ }^{20}$,the lesion occurs as a well- demarcated, symmetric, de-papillated area arising anterior to the circumvallate papillae ${ }^{20}$.

2.7.1 Clinical presentation: Central papillary atrophy appears as a well- demarcated erythematous zone that affects the midline, posterior dorsal tongue and is often asymptomatic. The erythema is due in part to the loss of filiform papillae in this area ${ }^{21}$.

The surface of the lesion can be smooth or lobulated. Most of the cases are asymptomatic, but some patients complain of persistent pain, irritation, or pruritus ${ }^{21}$.When it is concomitant with a palatal inflammation it is known as kissing lesion ${ }^{21}$. 
2.7.2 Treatment: Common median rhomboid glossitis treatment involves the use of antifungal remedies. These remedies are given in cases when candida is present, as it helps eliminate the candida and the inflammation associated with it. Raised lesions can be effectively removed with surgery $y^{20,21}$.

\subsection{ORAL HAIRY LEUKOPLAKIA}

It is a white, hyperplastic, vertically corrugated lesion. It is caused by Epstein-Barr virus and is usually associated with HIV infection or other immunosuppressive conditions. It might be the first sign of HIV infection in some patients ${ }^{22}$.

It has been indicated of depressed T-cell immunity.

2.8.1 Clinical presentation: It has been recognized as one of the oral manifestations of AIDS. Has been described as an asymptomatic, white plaque or corrugated lesion that commonly occurs on the lateral borders of tongue. Generally unilateral, sometimes can extend onto the dorsum of the tongue ${ }^{14}$.Sometimes when the lesion is symptomatic it exhibits features like burning sensation and taste alteration.

2.8.2 Treatment: Treatment for hairy leukoplakia is associated with the treatment of the underlying immunosuppressive disorder. If specific treatment is required then an antiviral drug may be prescribed. It might include acyclovir, famciclovir, or valacyclovir. In rare instances, the sore can be removed through a surgical procedure ${ }^{14,22}$.

\subsection{HYPOGLOSSAL NERVE PALSY}

Hypoglossal nerve palsy is an uncommon neurological abnormality that can provoke characteristic clinical signs which includes unilateral atrophy of the tongue musculature.

2.9.1 Clinical presentation: The main clinical feature of this disorder is the deviation of the tongue on the affected side upon protrusion. Paralysis/paresis of one side of the tongue results in ipsilateral curvature of the tongue i.e., the tongue will move towards the affected side $^{23}$.

If there is a central lesion, involvement is often bilateral. The patient cannot protrude the tongue, and attempt movement of tongue posteriorly is defective and uncoordinated.The abnormality of the tongue will lead to misarticulation. The individuals will have a problem in producing $\mathrm{t}, \mathrm{d}, \mathrm{n}, \mathrm{I}, \mathrm{j}, \mathrm{k}$ and $\mathrm{g}$ sounds. Isolated HNP in children is often an ominous sign of underlying malignancy.

2.9.2 Treatment: Speech therapy should be given.Treatment of hypoglossal nerve injuries due to penetrating wounds is surgical and the nerve tends to recover quite well ${ }^{23}$.

\subsection{CARCINOMA}

Squamous cell carcinoma is one of the most common malignant tumors of the skin and oral mucosa. The majority of these occur on the lower lip because of its great exposure to precipitating factors. It grows along the mucosal surfaces and infiltrates deeper structures in a predictable pattern. Tumors can spread by direct penetration, tracking along the nerve and vascular invasion routes. SCC of the lower lip invades the deep muscle and mandible.

The etiological factors responsible for SCC are multifactorial:

Extrinsic factors include tobacco smoke, alcohol, syphilis, and sunlight. Intrinsic factors include systemic or generalized states such as general malnutrition or iron deficiency anemia.

2.10.1 Clinical presentation: Patients may present with an awareness of a mass in the mouth or neck. Dysphagia, odynophagia, otalgia, limited movement, oral bleeding, neck masses, and weight loss can be noticed in advanced disease ${ }^{24}$.

Most often the precancerous lesions proceed to carcinoma which includes features like white, red or mixed red and white lesion; a change in the surface texture producing a smooth, granular, rough, or crusted lesion, or the presence of a mass or ulceration. The lesion can be flat or elevated and ulcerated or non-ulcerated and may be minimally palpable or indurated. Loss of function involving the tongue can affect speech, swallowing, and diet ${ }^{24}$. Lymphatic spread of oral carcinoma involves the submandibular and digastric nodes, the upper cervical nodes, and finally, the remaining nodes of the cervical chain ${ }^{24}$.

2.10.2 Treatment: The principle objective treatment is to cure the patient of oral cancer. The choice of treatment depends upon the degree of differentiation, the site and size of the primary lesion, lymph node status etc. If the lesion is not cured by initial therapy, surgery and radiation are used. Chemotherapy is an adjunct to the principal therapeutic modalities of radiation and surgery ${ }^{24}$. 


\section{Conclusion}

From what mentioned above, these are the most commonly occurring lesions on the lips and the tongue due to various etiological factors. This review article mainly concentrates on the various clinical aspects of the above mentioned lesions. They stress the importance for a better understanding of their existence which would favor a suitable treatment modality for their cure.

\section{References}

[1] Neville, Damm, Allen, Bouquot. Developmental Defects of the Oral and Maxillofacial Region. In: Oral and Maxillofacial Pathology. $3^{\text {rd }}$ ed. Noida: Elsevier; 2009.p.14.

[2] RenataAparecida, Martinez Antunes, Ribeiro Vieira, Eliana Maria, Minicucci, Mariangela Esther et al. Actinic cheilitis and squamous cell carcinoma of the lip: Clinical, histopathological and immunogenetic aspects. An Bras Dermatol. 2012; 87(1):105-14.

[3] Neville, Damm, Allen, Bouquot. Developmental Defects of the Oral and Maxillofacial Region. In: Oral and Maxillofacial Pathology. $3^{\text {rd }}$ ed. Noida: Elsevier; 2009.p.13-4.

[4] MousumiGoswami, Sanjay Singh, [...], Amit Singh. Lymphangioma of the tongue.Natl J Maxillofac Surg. 2011 Jan-Jun; 2(1): 86-8.

[5] Neville, Damm, Allen, Bouquot. Developmental Defects of the Oral and Maxillofacial Region. In: Oral and Maxillofacial Pathology. $3^{\text {rd }}$ ed. Noida: Elsevier; 2009.p.538-9.

[6] RathyRavindran, AnilaKarunakaran. Idiopathic Orofacial Granulomatosis with Varied Clinical Presentation.Hindawi Publishing Corporation, Case Reports in Dentistry; Volume 2013, Article ID 701749, 3 pages.

[7] B. Senthilkumar, M. NazargiMahabob. Mucocele: An unusual presentation of the minor salivary gland lesion.J Pharm BioalliedSci. 2012 August; 4(Suppl 2): S180-S182.

[8] Neville, Damm, Allen, Bouquot. Developmental Defects of the Oral and Maxillofacial Region. In: Oral and Maxillofacial Pathology. $3^{\text {rd }}$ ed. Noida: Elsevier; 2009.p.454-5.

[9] Neville, Damm, Allen, Bouquot. Developmental Defects of the Oral and Maxillofacial Region. In: Oral and Maxillofacial Pathology. $3^{\text {rd }}$ ed. Noida: Elsevier; 2009.p.404

[10] Curtis W. Archibald, MD, Karim G. Punja, MD, Allan F. Oryschak, MD. Orofacial granulomatosis presenting as bilateral eyelid swelling.Saudi Journal of Ophthalmology (2012) 26.p 177-79.

[11] MousumiGoswami, Sanjay Singh, [...], Amit Singh. Lymphangioma of the Tongue.Natl J Maxillofac Surg. 2011 Jan-Jun; 2(1): 8688.

[12] Neville, Damm, Allen, Bouquot. Developmental Defects of the Oral and Maxillofacial Region. In: Oral and Maxillofacial Pathology. $3^{\text {rd }}$ ed. Noida: Elsevier; 2009.p.538-9.

[13] Neville, Damm, Allen, Bouquot. Developmental Defects of the Oral and Maxillofacial Region. In: Oral and Maxillofacial Pathology. $3^{\text {rd }}$ ed. Noida: Elsevier; 2009.p.13-5.

[14] Alexander Kreuter MD, Ulrike Wieland MD. Oral hairy leukoplakia: A Clinical Indicator of Immunosuppression, CMAJ, May 17;2011.p. 183(8).

[15] Neville, Damm, Allen, Bouquot. Developmental Defects of the Oral and Maxillofacial Region. In: Oral and Maxillofacial Pathology. $3^{\text {rd }}$ ed. Noida: Elsevier; 2009.p.408-9.

[16] LIGIA STĂNESCU, E. F. GEORGESCU, CRISTIANA SIMIONESCU, IULIANA GEORGESCU. Lymphangioma of the oral cavity.Romanian Journal of Morphology and Embryology 2006. 47(4):373-377

[17] Neville, Damm, Allen, Bouquot. Developmental Defects of the Oral and Maxillofacial Region. In: Oral and Maxillofacial Pathology. $3^{\text {rd }}$ ed. Noida: Elsevier; 2009.p.547.

[18] Guang-Zhi Yang, Jing Li and Hua Jin, Yang et al.Giant mesenteric hemangioma of cavernous and venous mixed type: A rare case report. BMC Surgery 2013, 13:50 Page 2 of 4.http://www.biomedcentral.com/1471-2482/13/50

[19] Sergio vaÑÓ-galvÁn, md, Pedro JaÉn, phd. The Clinical Picture: Black hairy Tongue. Cleveland Clinic Journal of Medicine. Volume 75, number 12; dec 2008; .p. 847.

[20] Mustafa Goregen, OzkanMiloglu, [...], AyseEsinAktas. Median Rhomboid Glossitis: A Clinical and Microbiological Study. Eur J Dent. 2011 October; 5(4): p.367-372.

[21] Neville, Damm, Allen, Bouquot. Developmental Defects of the Oral and Maxillofacial Region. In: Oral and Maxillofacial Pathology. $3^{\text {rd }}$ ed. Noida: Elsevier; 2009.p.216.

[22] Ajay Reginald, B. Sivapathasundharam. Oral hairy leukoplakia: An exfoliative cytology study. ContempClin Dent. 2010 JanMar; 1(1): p.10-13.

[23] http://www.slideshare.net/sungayathri/hypoglossal-nerve-palsy

[24] Neville, Damm, Allen, Bouquot. Developmental Defects of the Oral and Maxillofacial Region. In: Oral and Maxillofacial Pathology. $3^{\text {rd }}$ ed. Noida: Elsevier; 2009.p.409-21. 